\title{
Still Grappling With Menstrual Hygiene: Explaining Uptake By Socio-Cultural Factors Among School Going
} Girls in Kenya

\author{
Mary Wambui Mathenge ${ }^{1}$ and Ronnie Midigo ${ }^{2 *}$ \\ ${ }^{1}$ Great Lakes University of Kisumu, Kenya \\ ${ }^{2}$ University of Nairobi, Kenya
}

Correspondence to: Ronnie Midigo, University of Nairobi, Kenya; E-mail: ronniemidigo@gmail.com

Received date: March 21, 2020; Accepted date: March 27, 2020; Published date: April 7, 2020

Citation: Mathenge MW, Midigo R (2020) Still Grappling With Menstrual Hygiene: Explaining Uptake By Socio-Cultural Factors Among School Going Girls in Kenya. J Obst Gynecol Surg. 1 (1): pp. 1-6.

Copyright: (C2020 Mathenge MW, et al. This is an open-access article distributed under the terms of the Creative Commons Attribution License, which permits unrestricted use, distribution and reproduction in any medium, provided the original author and source are credited.

\section{ABSTRACT}

Globally, approximately $52 \%$ of the female population ( $26 \%$ of the total population) is of reproductive age. Most of these women and girls will menstruate each month for between two to seven days. Menstrual hygiene is an important part of the basic hygiene, sanitation, and reproductive health services to which every woman and girl has a right. Most girls lack adequate information on menarche, puberty, and Menstrual Hygiene Management. This predisposes them to reproductive tract infections. This study sought to establish the socio-cultural factors influencing the adoption of menstrual hygiene practices among adolescent girls in public secondary schools in Malindi Sub County. The study adopted a cross-sectional analytical. Data was collected using both qualitative and quantitative methods. The study established that most of the school-going adolescents in Malindi Subcounty (64\%) have good menstrual hygiene practices. The socio-cultural factors influencing menstrual hygiene practices include cultural expectations, provisions, restrictions and cultural significance, religious restrictions and parent's levels of education $(P>0.05)$. Future studies could investigate the influence of structural factors both in the general environment, the school and the households where these adolescents come from. The study also recommends awareness drives on the importance of menstrual hygiene among adolescents and the development and implementation of policies on menstrual hygiene practices.

\section{Keywords:}

Menstrual hygiene, Culture, Menarche, Sanitary towels

\section{Introduction}

For girls, puberty means the onset of menarche and a time when they increase their intellectual capacities and experience moral development. Every learner has a right to a safe and healthy environment in which to develop and realize their full potential. Every learner has a right to a safe and healthy environment in which to develop and realize their full potential. However, in most communities, menstruation is considered a private and personal issue making it difficult to discuss it in public, for instance in a classroom set up. Coupled with other factors, poor menstrual hygiene practices continue to be experienced among most girls in schools.

Despite menstruation being a natural process, majority of menstruating girls do not have access to clean and safe sanitary products, nor to a clean and private space in which to change menstrual cloths or pads, nor to a private space in which to wash. Poor menstrual hygiene practices have been associated with urinary tract infections. Therefore, implies that proper sanitary hygiene practices are important for the prevention of such infections [1]. A study conducted by Anand, et al. [2] in India revealed that menstrual hygiene practices are associated with the socio-economic status of women. Other studies have linked menstrual hygiene practices to cultural and social factors [3]. Such studies have not concentrated on the situation of school-going children. A study to establish socio-cultural factors influencing the adoption of menstrual hygiene practices among the secondary school-going adolescent girls in Kilifi County would bring to light the gravity of the situation and how it affects the adolescent girls.

\section{Methodology}

This was an analytical cross-sectional study aimed at establishing the socio-cultural factors influencing the adoption of menstrual hygiene practice among adolescent girls in public secondary schools in Malindi Sub-County. The study population comprised all public secondary school going girls of age, (1419) years in Malindi Sub-County. A total of 358 respondents were sampled randomly to participate in the study. Data was collected using self-administered structured questionnaires filled by the students under the guidance of the researcher as well as Focused Group Discussion (FGD) and Key Informant Interview (KII). Quantitative data analysis was done using descriptive statistics and summarized in charts and tables. Inferential statistics, such as chi-square tests and regression analysis. Frequencies for the numerical variables including age, age at menarche, parents' level of education, occupation, marital status, and average monthly income are presented in frequency tables. Qualitative data were thematically analyzed. The analysis was assisted by a qualitative data analysis software (NVIVO Version 8).

\section{Results}

\section{Demographic Characteristic of study population}

Demographic factors investigated included levels of education, 
Citation: Mathenge MW, Midigo R (2020) Still Grappling With Menstrual Hygiene: Explaining Uptake By Socio-Cultural Factors Among School Going Girls in Kenya. J Obst Gynecol Surg. 1 (1): pp. 1-6..

age, onset of menarche, menstrual cycle menstrual flow period and ethnicity (Table 1).

Table 1: Demographic characteristics of the respondents.

\begin{tabular}{|c|c|c|c|}
\hline & & Frequency & Percent \\
\hline \multirow[t]{4}{*}{ Level of Education } & Form 1 & 110 & 28.6 \\
\hline & Form 2 & 115 & 29.9 \\
\hline & Form 3 & 105 & 27.3 \\
\hline & Form 4 & 54 & 14.1 \\
\hline \multirow[t]{3}{*}{ Age } & $<=16$ & 147 & 38.3 \\
\hline & $17-18$ & 179 & 46.6 \\
\hline & $19+$ & 58 & 15.1 \\
\hline \multirow[t]{3}{*}{ Onset of Menarche } & $<=11$ & 5 & 1.3 \\
\hline & $11-15$ & 265 & 69 \\
\hline & $15+$ & 114 & 29.7 \\
\hline \multirow[t]{4}{*}{ Menstrual Cycle } & 30 Days & 22 & 5.7 \\
\hline & 28 Days & 191 & 49.7 \\
\hline & Irregular & 99 & 25.8 \\
\hline & Don't Know & 72 & 18.8 \\
\hline \multirow[t]{4}{*}{ Menstrual Flow Period } & 2 Days & 10 & 2.6 \\
\hline & 3 Days & 131 & 34.1 \\
\hline & 4 Days & 212 & 55.2 \\
\hline & Don't Know & 31 & 8.1 \\
\hline \multirow[t]{4}{*}{ Ethnicity } & Kamba & 16 & 4.2 \\
\hline & Pokomo & 19 & 4 \\
\hline & Mijikenda & 318 & 82.8 \\
\hline & Others & 25 & 96.5 \\
\hline
\end{tabular}

From Table 1 above, Students in form 1 were $28.6 \%$, those in form 2 were $29.9 \%$ while those in form 3 were $27.3 \%$. Most of the students were aged $17-18$ years (46.6\%). Those with 28 days menstrual cycle were $46.6 \%$ while those with irregular menstrual cycles were $25.8 \%$. Also, most respondents indicated that the onset of their menstrual cycle was when they were between $14-15$ years (69\%). The study also established that most of the respondents (55.2\%) had 4 days of menstrual flow and another $34.1 \%$ indicated that they had 3 days of menstrual flow.

\section{Menstrual hygiene practices among respondents}

To investigate the status of menstrual hygiene practices, measures focusing on the use of material during menstruation were used where 1 point was assigned for use of sanitary pad, 0 for other sanitary materials. Also, a method of disposal of materials was used where 0 was awarded for open field and 1point for another proper disposal. Cleaning of external genitalia practices was also used where 1 point was awarded for cleaning 2 or more times/day, 0 for less than 2 times a day. Further materials used for cleaning purpose was also used where 1 point was awarded for washing with soap and water or with plain water, and 0 for not washing. Respondents who scored 5-9 points were adjudged as having good practice and respondents who scored 0-4 points were adjudged as having poor practices (Table 2).

Table 2: Hygiene practices.

\begin{tabular}{|l|l|l|l|}
\hline \multirow{2}{*}{ Materials used during menstruation } & Hygiene practice & Frequency & Percentage \\
\cline { 2 - 4 } & Sanitary pads & 257 & 66.9 \\
\cline { 2 - 4 } & Other sanitary materials & 127 & 33.1 \\
\hline \multirow{3}{*}{ Methods of disposal } & Latrine & 118 & 30.7 \\
\cline { 2 - 4 } & Open field disposal & 48 & 12.5 \\
\cline { 2 - 4 } & Waste bins & 218 & 56.8 \\
\hline Cleaning of external genitalia & 2 or more times & 62 & 16.1 \\
\cline { 2 - 4 } & Less than twice & 322 & 83.9 \\
\hline
\end{tabular}


Citation: Mathenge MW, Midigo R (2020) Still Grappling With Menstrual Hygiene: Explaining Uptake By Socio-Cultural Factors Among School Going Girls in Kenya. J Obst Gynecol Surg. 1 (1): pp. 1-6..

\begin{tabular}{|l|l|l|l|}
\hline Materials used for cleaning & $\begin{array}{l}\text { Soap and water/plain } \\
\text { water }\end{array}$ & 251 & 65.4 \\
\cline { 2 - 4 } & Not washing & 133 & 34.6 \\
\hline
\end{tabular}

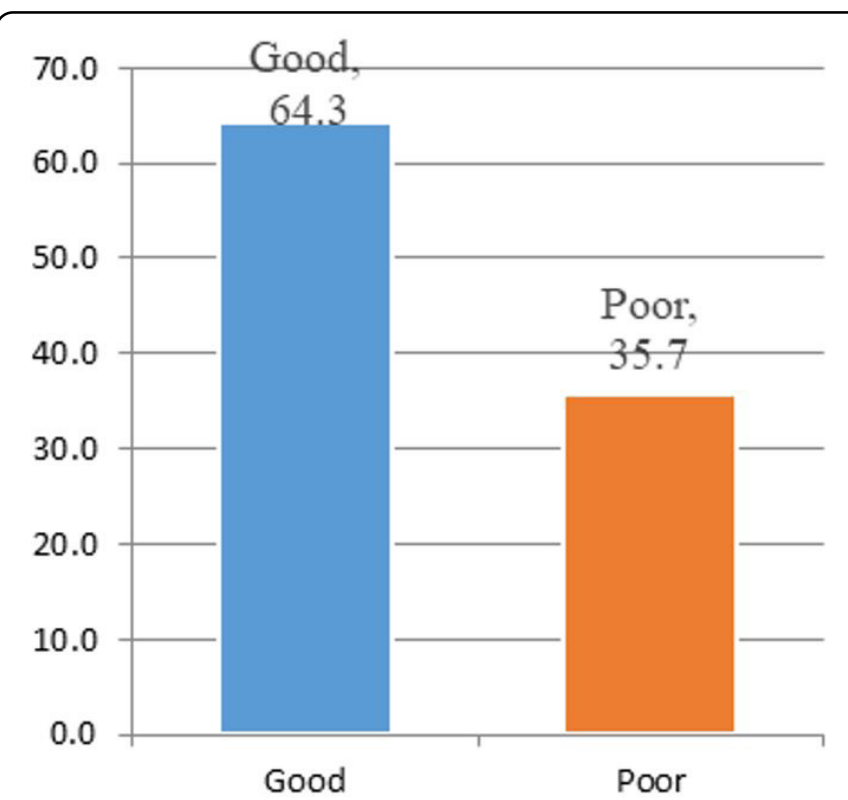

Figure 1: Proportion of respondents with good menstrual hygiene practices.

Table 3: Cultural factors influencing adoption of menstrual hygiene practices.

\begin{tabular}{|c|c|c|c|c|c|c|}
\hline & & & Poor & Good & OR & $\mathrm{P}$ \\
\hline \multirow{3}{*}{$\begin{array}{l}\text { My culture expects } \\
\text { limited/controlled } \\
\text { discussions on sexuality }\end{array}$} & Yes & 157 (40.9) & 43 & 114 & 1 & \multirow{3}{*}{$\begin{array}{l}X^{2}=23.31, D F=3, \\
p<0.0001\end{array}$} \\
\hline & No & $197(51.3)$ & 73 & 124 & $0.6(0.41,1.0)$ & \\
\hline & Don't Know & $30(7.8)$ & 22 & 8 & $0.1(0.06,0.33)$ & \\
\hline \multirow{3}{*}{$\begin{array}{l}\text { My culture provides } \\
\text { specific ways of disposing } \\
\text { menses }\end{array}$} & Yes & $48(12.5)$ & 36 & 12 & 1 & \multirow{3}{*}{$\begin{array}{l}X^{2}=90.13, D F=2, \\
p<0.0001\end{array}$} \\
\hline & No & 267 (69.5) & 55 & 212 & $11.6(5.64,23.7)$ & \\
\hline & Don't Know & $69(18.0)$ & 47 & 22 & $1.4(0.61,3.21)$ & \\
\hline \multirow{3}{*}{$\begin{array}{l}\text { My culture restricts } \\
\text { my activities during my } \\
\text { menstrual periods }\end{array}$} & Yes & 74 (19.3) & 51 & 23 & 1 & \multirow{3}{*}{$\begin{array}{l}X^{2}=99.4, D F=2, \\
P<0.0001\end{array}$} \\
\hline & No & $245(63.8)$ & 43 & 202 & $10.4(5.76,18.8)$ & \\
\hline & Don't Know & 65 (16.9) & 44 & 21 & $1.1(0.52,2.17)$ & \\
\hline \multirow{3}{*}{$\begin{array}{l}\text { Menstrual tissue has } \\
\text { cultural significance }\end{array}$} & Yes & 84 (21.9) & 62 & 22 & 1 & \multirow{3}{*}{$\begin{array}{l}X^{2}=41.48, D F=2, \\
P<0.0001\end{array}$} \\
\hline & No & $132(34.4)$ & 39 & 93 & $6.7(3.64,12.41)$ & \\
\hline & Don't Know & 68 (17.7) & 37 & 31 & $2.4(1.19,4.67)$ & \\
\hline
\end{tabular}

well as those who did not know such cultural expectations were less likely to have good menstrual hygiene practices ( 0.6 and 0.1 times respectively).

Respondents who indicated that their cultures provided ways for disposal of menses were less likely to have good menstrual hygiene practices. Those who were not aware of such cultural provisions, as well as those who were certain that such provisions did not exist, were 1.4 and 11.6 times more likely to have good menstrual hygiene practices respectively. Respondents who indicated that their cultures restricted their activities during menstrual periods were less likely to have good menstrual hygiene practices. Those who were not aware of such restrictions, as well as those who were certain of the absence of
During Key Informant Interviews with the Sub-County education officers, it emerged that most of the students enrolled in secondary schools in the region were accessing sanitary pads. One informant indicated that Most students can access sanitary pads. This is because of the government's efforts including subsidies on sanitary towels and also our partners have been running programs where students are supplied with sanitary towels for free (KII, Education Officer)

\section{Socio-Cultural factors influencing adoption of menstrual} hygiene practices

Socio-cultural factors investigated were divided into the cultural and social factors. Within cultural factors, cultural expectations, provisions, restrictions and significant issues with regards to menstrual hygiene were investigated. Such were cross-tabulated with the established menstrual hygiene practice scores and Chi-square tests conducted to ascertain relationships (Table 3).

The findings indicate that all the cultural factors were significantly associated with the adoption of menstrual hygiene practices $(p<0.05)$. respondents who indicated that their cultural expectations did not control discussions on sexuality as 
Citation: Mathenge MW, Midigo R (2020) Still Grappling With Menstrual Hygiene: Explaining Uptake By Socio-Cultural Factors Among School Going Girls in Kenya. J Obst Gynecol Surg. 1 (1): pp. 1-6..

Table 4: Regression analysis of the cultural factors against the adoption of menstrual hygiene practices.

\begin{tabular}{|l|l|l|l|l|l|l|l|}
\hline ANOVA & $\mathrm{df}$ & SS & R Square & F & Significance F & P-value & t Stat \\
\hline Regression & 1 & 203.1312 & 0.105798 & 1.183149 & 0.302237 & 0.000017 & 7.666497 \\
\hline Residual & 10 & 1716.869 & & & & & \\
\hline Total & 11 & 1920 & & & & & \\
\hline
\end{tabular}

The findings as presented in Table 4.6 above indicate a significant relationship between cultural factors and the adoption of menstrual hygiene practices ( $p=0.000017)$. the t-statistics obtained was 7.666497 .

Social factors investigated by the study included a person's menstrual issues that are shared with, parent's level of education, parent's marital status, religion, religious expectations, and religious restrictions. Chi-square tests were conducted upon cross-tabulation of the variables with the menstrual hygiene scores (Table 5).

Table 5: Social factors influencing the adoption of menstrual hygiene practices.

\begin{tabular}{|c|c|c|c|c|c|c|}
\hline & & Frequency & Poor & Good & OR & \\
\hline \multirow[t]{5}{*}{ Persons Shared with } & Mother & $173(45.1)$ & 66 & 107 & 1 & $X^{2}=3.0436$, \\
\hline & Father & $6(1.6)$ & 3 & 3 & $0.6(0.12,3.15)$ & $D F=3$, \\
\hline & Aunt & $57(14.8)$ & 19 & 38 & $1.2(0.66,2.32)$ & $P=0.3849$ \\
\hline & Sister & $14(3.6)$ & 8 & 6 & $0.5(0.15,1.39)$ & \\
\hline & Others & $134(34.8)$ & 42 & 92 & $1.4(0.84,2.18)$ & \\
\hline \multirow{4}{*}{$\begin{array}{l}\text { Parent's Level of } \\
\text { Education }\end{array}$} & Primary & $144(37.5)$ & 73 & 71 & 1 & $X^{2}=43.31$ \\
\hline & Secondary & 117 (30.5) & 38 & 79 & $2.1(1.29,3.55)$ & $D F=3$, \\
\hline & University & 74 (19.3) & 5 & 69 & $14.2(5.41,37.23)$ & $p<0.0001$ \\
\hline & None & $49(12.8)$ & 22 & 27 & $0.3(0.66,2.42)$ & \\
\hline \multirow[t]{5}{*}{ Parent's Marital Status } & Single & $91(23.7)$ & 35 & 56 & 1 & $X^{2}=0.842$ \\
\hline & Married & 199 (51.8) & 68 & 131 & $1.2(0.72,2.01)$ & $D F=4$, \\
\hline & Separated & 19 (4.9) & 8 & 11 & $0.9(0.31,2.35)$ & $p=0.8395$ \\
\hline & Widowed & 34 (8.9) & 12 & 22 & $1.1(0.5,2.6)$ & \\
\hline & Divorced & $41(10.7)$ & 15 & 19 & $0.8(0.36,1.76)$ & \\
\hline \multirow[t]{3}{*}{ Religion } & Christian & 369 (96.1) & 130 & 239 & 1 & $X^{2}=2.341$ \\
\hline & Muslim & $12(3.1)$ & 6 & 6 & $0.5(0.17,1.72)$ & $D F=2$ \\
\hline & Others & $3(0.8)$ & 2 & 1 & $0.3(0.02,3.03)$ & $p=0.3102$ \\
\hline \multirow[t]{3}{*}{ Religious Expectations } & Yes & $195(50.8)$ & 71 & 124 & 1 & $X^{2}=0.0385$, \\
\hline & & & & & & $D F=1$, \\
\hline & No & $189(49.2)$ & 67 & 122 & $1.0(0.69,1.58)$ & $p=0.8445$ \\
\hline \multirow[t]{3}{*}{ Religious Restrictions } & Yes & $123(32)$ & 56 & 67 & 1 & $X^{2}=7.231$ \\
\hline & & & & & & $D F=1$, \\
\hline & No & $261(68)$ & 82 & 179 & $1.8(1.17,2.84)$ & $p=0.0072$ \\
\hline
\end{tabular}

The findings indicate that parent's levels of education and religious restrictions had a significant relationship with the menstrual hygiene practices $(p<0.05)$. Respondents without religious restrictions were 1.8 times more likely to have good menstrual hygiene practices. Respondents whose parents had secondary school and university education had 2.1 and 14.2

odds of having good menstrual hygiene practices. Parents' level of education had the highest chi-square value $\left(X^{2}=43.31\right)$, followed by religious restriction $\left(X^{2}=7.231\right)$. Regression analysis revealed an insignificant relationship between social factors investigated and the adoption of menstrual hygiene practices. Table 5 below presents the findings.

Table 6: Regression analysis of the social factors against the adoption of menstrual hygiene practices.

\begin{tabular}{|l|l|l|l|l|l|l|l|}
\hline ANOVA & Df & SS & R Square & F & Significance F & P-value & t Stat \\
\hline Regression & 1 & 20777.91 & 0.87298 & 130.5822 & $5.89 \mathrm{E}-10$ & 0.357241 & 0.943556 \\
\hline Residual & 19 & 3023.231 & & & & & \\
\hline Total & 20 & 23801.14 & & & & & \\
\hline
\end{tabular}


Citation: Mathenge MW, Midigo R (2020) Still Grappling With Menstrual Hygiene: Explaining Uptake By Socio-Cultural Factors Among School Going Girls in Kenya. J Obst Gynecol Surg. 1 (1): pp. 1-6..

As indicated in Table 6 above, the relationship between social factors and the adoption of menstrual hygiene practices was insignificant $(p=0.357241)$. The test yielded a t-statistics of 0.943556 . Further analysis combining both the cultural and social factors revealed a significant relationship between socio-cultural factors and the adoption of menstrual hygiene practices (Table 7).

Table 7: Regression analysis of the socio-cultural factors against the adoption of menstrual hygiene practices.

\begin{tabular}{|l|l|l|l|l|l|l|l|}
\hline ANOVA & df & SS & R Square & F & Significance F & t Stat & P-value \\
\hline Regression & 1 & 14077.34 & 0.540378 & 36.44671 & $1.1 \mathrm{E}-06$ & 3.821044 & 0.000599 \\
\hline Residual & 31 & 11973.57 & & & & & \\
\hline Total & 32 & 26050.91 & & & & & \\
\hline
\end{tabular}

The findings of the study as indicated in Table 7 show a 3.821044 t-statistics at $p=0.000599$. This was at a $54 \%$ regression equation fit. From the Key informant interviews, it emerged that certain cultural beliefs and religious persuasions impact negatively on sexual and reproductive health in general. One of the respondents indicated that "You know within our cultures, most people cannot discuss issues to do with sexual health. We also have some religious groups which restrict women from certain activities when in their menstrual periods. It is such restrictions and dictates which may make a woman develop poor menstrual hygiene practices which then becomes a habit (KII, Education Officer)".

\section{Discussion}

\section{Menstrual hygiene practices among the respondents}

The study established that most respondents used sanitary pads during their menstrual period and that most of which disposed of used sanitary towels in waste bins. Cleaning of external genitalia by the respondents during their menstrual periods less than twice a day was recorded by a majority of the respondents. Most respondents also cleaned their external genitalia using soap and water or water alone. Menstrual hygiene scores revealed that a majority of the respondents had good menstrual hygiene practices. These findings may lead to an understanding that most of the secondary school students use sanitary pads. Notable challenge, however, was on the washing of the external genitalia where most students failed the minimum more than twice a day during menstrual periods. This could be attributed to a lack of information regarding sanitary hygiene. In a study conducted, Kuhlmann., Henry \& Wall (2017), girls had extremely limited information about why they menstruate and how to manage their menstrual flows hygienically and safely. Another study conducted by MacLean, Hearle \& Ruwanpura (2020) in Kenya noted that while the availability of sanitary towels in Kenya is ensured, its accessibility for young girls is still a problem. It could also be reasoned that other factors including cultural, social and economic could also influence the apparent lack of knowledge on menstrual hygiene.

\section{Socio-Cultural factors influencing adoption of menstrual hygiene practices}

The study established that socio-cultural factors including cultural expectations, provisions, restrictions and cultural significance, religious restrictions and parent's levels of education influenced MHP. While cultural issues and religious restrictions had a negative influence on menstrual hygiene practice, good menstrual hygiene practices improved with the parent's levels of education. The presence of cultural restrictions was highly associated with poor menstrual hygiene practices. These findings may lead to an understanding that culture plays a significant role in modeling perceptions associated with menstrual hygiene practices and that such perceptions greatly influence decisions made towards achieving menstrual hygiene standards. In cases where parents are educated, the findings of this study may lead to an understanding that parents who are educated are more likely to ensure that their daughters had good menstrual hygiene practices. While cultural and religious restrictions regarding sexual and reproductive health are well documented, the findings of this study point to a trend of cultural perceptions developed by the very individuals with regards to their sexuality based on their own interactions with culture and religion as independent agents. Previous studies including those of Pearce (2019), documented instances where adolescents were reluctant to share their concern about reproductive and sexual health with their parents due to fear of parents' suspicion and attributed this to the culture of avoidance. The current study thus reveals that girls as independent agents also make decisions which restrict their sexuality based on their interactions with their cultures and religion

\section{Conclusion and Recommendations}

The study concludes that over $60 \%$ of the school-going adolescents in Malindi Sub-county have good menstrual hygiene practices. Menstrual hygiene practices of the adolescents are influenced by socio-cultural factors including cultural expectations, provisions, restrictions and cultural significance, religious restrictions and parent's levels of education. Based on these findings, future studies could investigate the influence of structural factors both in the general environment, the school and the households where these adolescents come from. Awareness drives could be organized by the ministry of health as well as non- governmental organizations implementing sexual and reproductive health on the importance of menstrual hygiene among the adolescents. The findings of this study also lead to a recommendation on the need to develop and implement policies with guidelines on recommended menstrual hygiene practices. Such policies could be enacted and implemented by the Ministry of education.

\section{References}

1. Das P, Baker KK, Dutta A, et al. (2015) Menstrual hygiene practices, WASH access and the risk of urogenital infection in women from Odisha, India. PloS one. 10 (6): pp. e0130777.

2. Anand E, Singh J, Unisa S (2015) Menstrual hygiene practices and its association with reproductive tract infections and abnormal vaginal discharge among women in India. Sexual \& 
Citation: Mathenge MW, Midigo R (2020) Still Grappling With Menstrual Hygiene: Explaining Uptake By Socio-Cultural Factors Among School Going Girls in Kenya. J Obst Gynecol Surg. 1 (1): pp. 1-6..

Reproductive Healthcare. 6 (4): pp. 249-254.

3. House S, Mahon T, Cavill S (2013) Menstrual hygiene matters: a resource for improving menstrual hygiene around the world. Reproductive Health Matters. 21 (41): pp. 257-259.

4.http://www.communityledtotalsanitation.org/sites/ communityledtotalsanitation.org/files/MHM_Indonesia.pdf

5. Kuhlmann AS, Henry K, Wall LL (2017) Menstrual hygiene management in resource-poor countries. Obstetrical \& gynecological survey. 72 (6): pp. 356-359.
6. MacLean K, Hearle C, Ruwanpura KN (2020) Stigma of staining? Negotiating menstrual taboos amongst young women in Kenya. In Women's Studies International Forum. 78 (2): pp. 102290.

7. Pearce AM (2019) Access to and knowledge of sexual and reproductive health services among adolescent school girls in Gobabis, Namibia (Doctoral dissertation, University of Namibia). 